\title{
Fluvoxamine Measurement
}

National Cancer Institute

\section{Source}

National Cancer Institute. Fluvoxamine Measurement. NCI Thesaurus. Code C147340.

The determination of the amount of fluvoxamine present in a sample. 